\title{
BUSE SARIKAYA
}

Amasya Univeresity, Turkey

buse.sarikaya@amasya.edu.tr

\section{UNBALANCED DISTRIBUTION OF FOOD}

\begin{abstract}
While people starve every day, food is being wasted. Simultaneously a food shortage does not exist on our planet. There is no lack of food. Production and distribution are the two primary causes of this problem. Unbalanced nutrition is the cause of obesity, overweight and hunger. Insufficient food intake causes nutritional problems such as vitamin and Iodine deficiency, Anaemia, Underweight and Stunting, Low birth weight, Protein-Energy Malnutrition, excess intake of food causes. However, nutritional health problems are not only caused by the absense of food but also from excessive food intake causing diabetes, hypertension, heart diseases etc. These all health problems effect societies worldwide. Bringing the global burden of diet-related noncomunicable diseases under control and enhancing public nutrition and health requires a muti-diciplinary approach.
\end{abstract}

Keywords: food distribution; unbalanced nutrition; common nutritional problems in Society; malnutrition; obesity.

\section{UNBALANCED DISTRIBUTION OF FOOD: HUNGER AND OBESITY}

While people starve every day, food is being wasted. Simultaneously a food shortage does not exist on our planet. There is no lack of food. Production and distribution are the two primary causes of this problem. As the title of this article states, unbalanced nutrition is the cause of obesity, overweight and hunger. However, nutritional health problems are not only caused by the absense of food but also from excessive food intake (Waterlander 2017).

Global nutrition styles are of great concern. The number of obese and overweight people increased to 2.1 million in 2013 (Ng 2014), simultaneously 842 million people are at risk of malnutrition globally (FAO 2013). In addition, this widespread burden of diet-related noncomunicable diseases such as diabetes, hypertension, heart diseases etc. are among the main health problems effecting societies worldwide (Amuna and Zotor 2008, Lim 2012, Ministry of Health 2013, United Nations 2011, World Health Organization 2012). Furhermore, these diseases constitute an impediment to achieving development goals which include economic development, poverty reduction and health services (Beaglehole 2011). Bringing the global burden of diet-related noncomunicable diseases under control and enhancing public nutrition and health requires a muti-diciplinary approach (Otero 2015, Waterlander and Zenk 2015). Public health interventions such as 
school programmes, food labeling or nutrition education are not enough to overcome nutritional problems (Swinburn 1999, Swinburn 2011).

What is more important? These interventions do not counter the strong societal forces of cost, comercialization and availability that exist within the food industry. Even if they cause individual behavioural change, they can not meet the most vulnerable populations of society who desperately need access to food. Most people do not have the information about how public health interventions must operate within the overall food system and economy in general and globally. Historically, technical innovations, industrialization, investment and technology facilitate to supply our food requirements. What are these advantages? Food has become more available, accessible, affordable and varied. Famine and hunger have almost disappeared in delevoped countries (Tillotson 2004). However, our developed food technology system also threatens to overbalance the sustainability of our planet in terms of biodiversity, ecosystem degradation and green house gas emissions (Swinburn 2011, Lang 2009, McMichael 2007, O'Kane 2012). Developing countries are similarly hampered by lack of food distrubition. Consequently, global surplus food production and widespread hunger both exist at the same time and this is unfair (Pinstrup-Andersen 2002), one-third of the global food supply is being wasted (FAO 2013).

The world has become more aware of the crisis of food waste after the United Nations' Food and Agriculture Organisation's (FAO) report, which stated that one third of the produced food is lost or wasted, an amount of 1.3 billion tons is wasted anually. This level of waste also has negative implications with regard to other resources such as water, cropland and energy consumption (Kummu 2012). Moreover, the whole supply chain has been affected by food waste from agriculture, fishing and household consumption. According to Food and Agriculture Organisation's (FAO) statics, globally 800 million people are suffering from undernutrition (FAO 2015). Food insecurity is a significiant issue even in developed countries. In Europe approximately 43.6 million people were estimated to be at risk of food insecurity (Gentilini 2013), concurrently the food waste of European countries was reported as $179 \mathrm{~kg}$ per person per every year (O'Connor 2013). Even if different approaches are followed to ensure food security such as increasing production and distribution efficiency, food waste related figures suggest that one of the possible options to solve this problem is reducing the amount of food wasted (Evans 2012, 2013; Garnett 2014).

Reducing food waste is a global priority not only to protect natural resources but also to combat food insecurity. Waste reduction is directly related to controlling surplus food effectively. Surplus food can be defined as "edible food that is produced, retailed, manufactured or served but can not be sold or consumed for several reasons" (Garrone 2014). Critical and timely interventions to reduce food waste degradation are preventing the production of surplus food on time and managing it after the food is produced on site. Food waste hierarchy is a model which is discussed in a few articles and can be defined as managing surplus food. But there is not much information about operational processes, structural priorities and intentional strategies which make it both cost-effective and practicable within companies. Redistributing surplus food to food aid organisations and food banks is recommended in terms of consequences to social benefit but few studies exist which examine the important factors behind this Project (Papargyropoulou 2014). In 
consequence, the food waste hierarchy model should provide innovative operational tools which can be used to control and ensure food distribution equally, efficiently and effectively after it is produced. All food companies should have access to and benefit from these tools (Garrone 2016).

\section{WHO STARVES? USE OF TERMINOLOGY}

Malnourishment and obesity are the main public health problems which both cause many complications, including progressive risk factors that may end with death, from several diseases.

Food safety arises when everyone has physical, social and economic access to adequate, safe and nutritious food that covers dietary their needs and allows for a healthy active life. Households are an important basis for this practice at a family level.

Food insecurity arises when people do not have adequate physical, social and economic access to food.

Nutrition security arises from a healthy sanitary environment, adequate health services and health care and food security which create a healthy life for all household members.

Undernourishment arises when energy intake is below the minimum dietary energy requirement.

Undernutrition arises when food intake is insufficient, resulting in one or more of the following: thin for height (wasted), short for age ( stunted), underweight for age, inadequate vitamin/ mineral intake ( micronutrient malnutrition)

Malnuourishment arises when dietery intake is inadequate, such as an excess or imbalance in energy, protein and micronurients, nutritional deficiencies. Malnourishment includes undernutrition, overweight and obesity (Parakash 2014).

\section{NUTRITONAL HEALTH PROBLEMS CAUSES BY UNDERNOURISHMENT VITAMIN A DEFICIENCY}

Vitamin A, assessed by measuring serum retinol level, is deficient in approximately 163 million children in developing countries (30\%). While South central Asia has the highest prevalence along with central and west Africa with prevalence more than $40 \%$, South and central America and the Caribbean have the lowest with prevalence approximately $10 \%$. Two thirds of the affected are children in South central Asia. More effective interventions such as expanded fortification of Vitamin A are required to reduce Vitamin A deficiency at an accelerated rate (WHO 2009).

\section{IODINE DEFICIENCY DISORDERS}

The main solution to reduce prevalance of iodine deficiency disorders is coverage of iodized salt. Before 1990s, increased coverage of iodized salt was associated with lower goitre rate. The goitre rate decreased from $12.0 \%$ to $10,5 \%$ by iodization in the years between 1995- 2000 (UNSCN 2010).

\section{ANAEMIA}


Anemia, assessed by measuring haemoglobin levels, is especially a persistent nutritional problem in women and 40\% women in Asia and Africa, 25\% women in South America and Caribbean are anemic (estimated approximately 500 million). Iron deficiency in children has been related with constraining cognitive development so it should be an issue of concern in terms of education and fostering human capital. What is the role of a Countries priorities and programmes to decrease anemia? In general, anaemia is expected to decrease with diet and enhanced bioavailability of iron and better public health. Iron supplementation in schools may have a role in decreasing anaemia in adolescence. Widespread fortification of iron should be part of solution (UNSCN 2010).

\section{BEING UNDERWEIGHT OR SUFFERING FROM STUNTED GROWTH}

Child malnutrition is often reflected by stunted growth in Caribbean area and in the Americas. Stunting prevalance differs between 30-50\% in some countries such as Bolivia, Guatemala, Haiti, Honduras, Peru (WHO 2010). In developing regions prevalance decreases to $19 \%$ in 2007 (UNICEF 2009). In Africa and Asia, the rates of being underweight or suffering from stunted growth appear to be smilar. The rates of improvement are low. In China, the underweight prevalance was reported as $6.8 \%$ in children aged between $0-5$ years in 2002 , compared to previous years the prevalance has decreased, $18.7 \%$ in 1987 and 17,4\% in 1992 (WHO 2010). In India, underweight prevalance in childred aged between 0-3 years was reported $41.6 \%$ in 2002 (WHO 2010). We see a little bit of improvement from 44.4\% in 1998-1999. Child stunting trends are smilar to underweight in general. Countries do not improve gradually and permanently, rather they change from persistent high prevalences to low prevalences that are resistant. What is the way of rapid improvement and solution of malnutiriton in children? And can such solutions be started and supported by intervention programmes and deliberate policy decisions? Most long-term health and nutrition changes contribute and depend on broader trends. In general, both developed socioeconomic environments and health and nutrition programmes, which are supported economically are required. Community-based programmes have expanded so that people have contact and supported by community health and nutrition staff. These programmes should be the priority to improve nutritional status in general and be supported economically by the authorities.

\section{LOW BIRTH WEIGHT}

Low birth weigth is determined by low maternal pre-pregnancy body mass index and the mothers own low birth weight. Low birth weight is contributed to growth failure which is intergenerational. Low birth weight is directly linked to low body mass index in women. What is the solution? First, lowered low birth weight can be prevented by reducing births to adolescent mothers. Second improvements in women's nutrition and health. Third other considerations that support intrauterine growth.

The incidance of low birth weight is reported as $34 \%$ to $27 \%$ in South Asia , $18 \%$ to $12 \%$ per year over the past two decades. Asia still has the highest percentage of low birth weight babies. The prevalance increased to $18 \%$ (2000s) from $22 \%$ (1980s). 
Adolescence and child marriage subsist to be a strong social norm, especially in developing countries in central and western Africa, South and south east Asia. The age of marriage has a high correlation with age at first birth. Increasing the median age at marriage is generally associated with a lower incidance of low birth weight in Africa and Asia.

The policies and programmes such as implementing laws to prevent under-age marriage and helping girls to maintain their education and postpone pregnancies. In point of that fact, this could be a important factor in sustainably preventing the intergenerational transmission of malnutrition, accelerating transitions from high levels of low birth weight and malnutition to those seen in more developed countries, acceleration the progress towards normal growth and development.

The situation in underweight and stunting; sub-Saharan Africa has remained the same over the past twenty years. East Africa has shown some improvement (UNSCN 2010).

\section{PROTEIN - ENERGY MALNUTRITION}

Protein- energy malnutrition manifests in children as disorders called Kwashiorkor and Marasmus. Their clinical symptoms are different though many children have both of the symptoms.

Clinicians determined the differentiations between Kwashiorkor and Marasmus. Diagnosis of Kwashiorkor is observed by oedema through weight defects. Marasmus is simply severe cacexia from weight loss which genereally results as wasting. Malnutrition is defined as severe at $60 \%$ weight loss. (Parakash 2014).

Undernutrition and obesity are public health problems that can cause many complications and are risk factors for progression and death in several diseases.

\section{WHO IS EFFECTED BY BEING OVERWEIGHT OR OBESE?}

\section{Adults aged 18+}

Overweight and obesity are the main nutrition related diseases that lead to many adverse effects such as, insulin resistance, cholesterol, blood pressure, triglycerid levels, risks of coronary heart disease, ischemic stroke and type 2 diabeters mellitus (Bianchini 2002). Overweight and obesity is measured by body mass index a measure of weight relative to height.

\section{BODY MASS INDEX}

Increased body mass index is correlated with the risk of cancer of the breast, colon, prostate, endometrium, kidney and gall bladder. Also raised body mass leads to increased mortality rates. An optimum body mass index should be in the range of 21 to $23 \mathrm{~kg} / \mathrm{m}^{2}$ for elderly, while 18.9 to 24.9 for individuals.

Body mass index 25.0 to 29.9 leads to risk or co-morbidities and body mass index 30 or higher leads to severe risk of co-morbidities.

Nearly 2 billion adults were overweight and of these, more than half a billion were obese in 2014. Prevalances were measured as $39 \%$ of men and $40 \%$ of women aged over 18 were overweight (body mass index $\geq 25 \mathrm{~kg} / \mathrm{m}^{2}$ ) and $11 \%$ of men and $15 \%$ of women were obese. Both overweight and obesity have shown a significant increase over the last 40 years (WHO 2016). 
Figure 1. Age-standardized prevalence of obesity in men aged 18 years and over $\left(\mathrm{BMI} \geq 30 \mathrm{~kg} / \mathrm{m}^{2}\right), 2014$

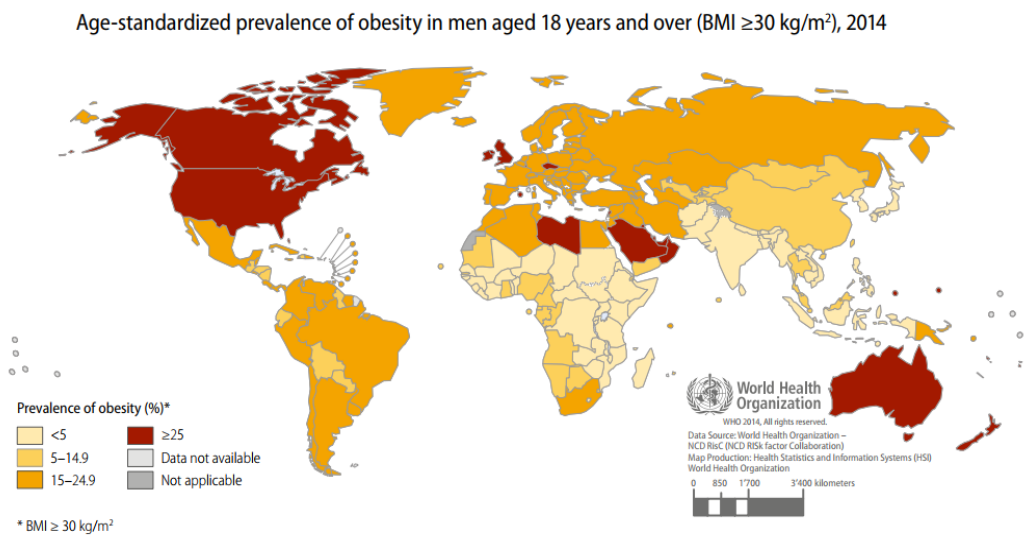

Source: World Health Organization - NCD RisC (NCD RISk factor Collaboration)

Figure 2. Age-standardized prevalence of obesity in women aged 18 years and over $\left(\mathrm{BMI} \geq 30 \mathrm{~kg} / \mathrm{m}^{2}\right), 2014$

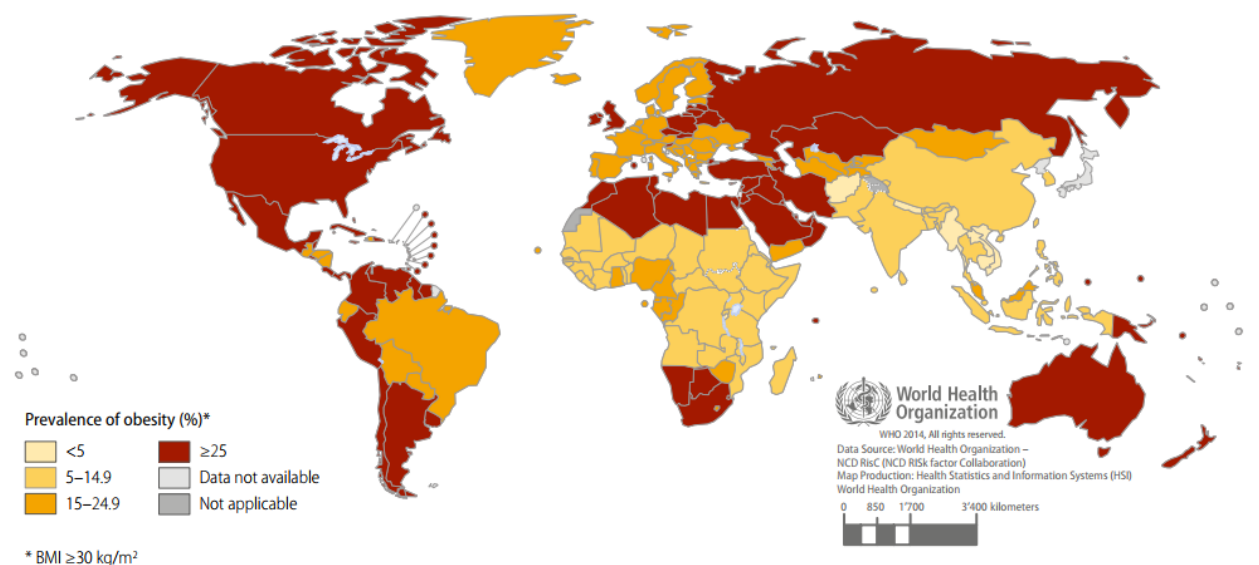

Source: Source: World Health Organization - NCD RisC (NCD RISk factor Collaboration).

\section{TH REPORT ON THE WORLD NUTRITION STATUS}

In 2013, the World Health Assembly decleared a global monitoring framework with 25 indicators and 9 voluntary global targets for 2025. This global status report on control and prevention on noncommunicable diseases. This report analyzes data 
on current status and identifies opportinities and priority actions for attaining the targets. All countries attain targets at different points in their progress.

Global target 1: $25 \%$ decrease in the prevelance mortality from cardiovascular diseases, cancer, diabetes or chronic respiratory diseases.

Global target 2: 10\% decrease in the harmful use of alcohol. Alcohol consumption ratio is the highest in European Region and America. There are cost-effective policy options to decrease the harmful use of alcohol. Pricing policies, reduced availability, marketing, drink-driving policies and individual interventions are included.

Global target 3: 10\% decrease in the prevalence of insufficient physical activity which countributes to 3.2 million deaths every year (Limm 2010). In $2010,23 \%$ of the adults and $81 \%$ of of adolescents aged between 11-17 were insufficently physically active (WHO 2014). WHO recommends 60 minutes of physical activity per day. Reaching the physical activity target requires multisectoral collabration between urban planning, use of transportation, recreaation, sports and education departments and create safe environments. Regular physical activity reduces the risk of stroke, diabetes, breast and colon cancer and the risk of ischaemic heart. Global target 4: $30 \%$ decrease in the intake of salt/sodium. Excess consumption of dietary sodium is associated with the risk of cardiovascular disease and hypertension. 1.7 million annual deaths from cardiovascular diseases have been attributed to excess sodium intake in global. Currently, around $10 \mathrm{~g}$ of salt ( $4 \mathrm{~g} /$ day of sodium) is suggested to consume daily (Mozaffarian 2014). Processed foods, ready to eat meals are the main source of salt. Policies aimed at decreasing salt consumption should be intersectoral and multidiscplinary.

Global target 5: 30\% decrease in the prevalance of current tobacco use. 6 million people die from tobacco use and 600.000 death to exposure to second-hand smoke (Oberg 2011; WHO 2014a). Interventions in tobacco use include: "100\% smoke-free"legislation, offering help to quit smoking, warning about the dangers, enforcing bans on tobacco advertising, raising tobacco taxes. In 2013, 95 countries had implemented at least one of the four tobacco control "best buy" interventions. Further interventions are required such as consolidation and maintenance of existing programmes, ultimately implemention of WHO Framework Convention on Tobacco Control.

Global target 6: $25 \%$ decrease in the prevalence of raised blood pressure which is attributed to 9.4 million deaths annually (Lim 2010). Uncontrolled hypertension causes stroke, cardiac failure, mycardial infarction, dementia, renal failure and blindness. The optimum blood pressure should be 140/90 $\mathrm{mmHg}$ as systolic/diastolic. The prevalence of raised blood pressure was $22 \%$ in 2014. Raised blood pressure has multifactoral reasons such as excessive salt and fat consumption, inadequate fruit and vegetable intake, overweight and obesity, insufficient physical activity, socioeconomic reasons, psychological stress. Worldwide interventions to hypertension are inadequate. 
Global target 7: Control over the rise in obesity and diabetes. Obesity leads to many adverse diseases such as diabetes, hypertension, coronary heart disease, stroke and many types of cancer. Obesity and diabetes can be controlled through multisectoral action that contributes to the production, distribution and marketing of the food. Weight control and rised physical activity can help.

Global target 8: At least implemending half of the drug users to receive drug theraphy and counselling to prevent heart attacks and strokes. Cardiovascular diseas is attributed to 17.5 million deaths in 2012 (WHO 2014b). The interventions include basic Technologies and medicines, the health workforce, service delivery, health information, referral.

Global target 9: $80 \%$ availability of the affordable basic technologies and esential medicines. These basic techologies include, measurement devices of blood pressure, blood sugar and cholesterol, weight and height scales.

Consequently, every excessive or deficient food intake has a negative and undesired effect on human health. Maintenance of human heath should be ensured with balanced nutrition.

\section{REFERENCES}

Amuna, Paul and Francis B. Zotor. 2008. "Epidemiological and nutrition transition in developing countries: impact on human health and development." Proceedings of the Neutrition Society 67(1): 82-90.

Beaglehole, Robert, Ruth Bonita, and Richard Horton. 2011. "Priority actions for the non-communicable disease crisis." The Lancet 377(9775):1438-1447.

Bianchini, Franca, Rudolf Kaaks and Harri Vainio. 2002. "Overweight, obesity, and cancer risk." The Lancet Oncology 3(9): 565-74.

Evans, David, Hugh Campbell, and Anne Murcott. 2013. "Waste Matters: New perspectives on Food and Society." Pp. 83-97 in The Sociological Review, edited by Evans, David, Hugh Campbell, and Anne Murcott. Oxford: Wiley-Blackwell.

Evans, David. 2014. Food Waste: Home Consumption, Material Culture and Everyday Life. London: Bloomsbury Academic.

Food and Agriculture Organization of the United Nations (FAO). 2015. Suite of Food $\begin{array}{lllll}\text { Security Indicators } & \text { Retrieved } & \end{array}$ (http://faostat3.fao.org/browse/D/FS/E)

Food and Agriculture Organization of the United Nations (FAO). 2013a. "Food Wastage Footprint. Impacts on Natural Resources" (Rome (Italy)). Retrieved July 27, 2017 (http://www.fao.org/docrep/018/i3347e/i3347e.pdf)

Garnett, Tara. 2014. "Three perspectives on sustainable food security: efficiency, demand restraint, food system transformation. What role for life cycle assessment?" Journal of Cleaner Production 73: 10-18. 
Garrone, Paola, Marco Melacini, and Alessandro Perego. 2016. "Reducing food waste in food manufacturing companies." Journal of Cleaner Production 137: 1076-1085.

Garrone, Paola, Marco Melacini, Alessandro Perego. 2014. "Opening the black box of food waste reduction." Food Policy 46: 129-139.

Gentilini, Ugo. 2013. Banking on Food: the State of Food Banks in High-income Countries. Brighton: Institute of Development Studies.

Kummu, Matti, Hans de Moel, and Miina Porkka. 2012. "Lost food, wasted resources: global food supply chain losses and their impacts on freshwater, cropland, and fertiliser use." Science of The Total Environment 438: 477-489.

Lang, Tim, David Barling, and Martin Caraher. 2009. Food Policy Integrating Health, Environment and Society. Oxford: Oxford University Press.

Lim, Stephen. 2012. "A comparative risk assessment of burden of disease and injury attributable to 67 risk factors and risk factor clusters in 21 regions, 1990-2010: a systematic analysis for the Global Burden of Disease Study 2010." The Lancet 380 (9859): 2224-60.

McMichael, Anthony J. 2007. "Food, livestock production, energy, climate change, and health." The Lancet 370 (9594): 1253-1263.

Mozaffarian, Dariush. 2014. "Global Burden of Diseases Nutrition and Chronic Diseases Expert Group. Global sodium consumption and death from cardiovascular causes." The New England Journal of Medicine 371(7): 624-34.

Ng, Marie, Tom Flewing and Margaret Robinson. 2014. „Global, regional, and national prevalence of overweight and obesity in children and adults during 1980-2013: a systematic analysis for the Global Burden of Disease Study 2013.” The Lancet 384 (9945): 766-781.

Oberg, Mattias. 2011. „Worldwide burden of disease from exposure to second-hand smoke: a retrospective analysis of data from 192 countries." The Lancet 377(9760):139-46.

O'Connor, Clementine. 2013. "Quantification of Food Waste in the EU.” OECD Food $\begin{array}{lllll}\text { Chain Network. } & \text { Retrieved } & 2017\end{array}$ (http://www.oecd.org/site/agrfcn/Session\%201_ClementineOConnor.pdf)

O'Kane, Gabrielle. 2012."What is the real cost of our food? Implications for the environment, society and public health nutrition." Public Health Nutrition 15(2): 268-276.

Otero, Gerardo, Gabriela Pechlaner, Giselle Liberman. 2015. „The neoliberal diet and inequality in the United States." Social Sciences and Medicine 142: 47-55.

Papargyropoulou, Effie. 2014. „The food waste hierarchy as a framework for the management of food surplus and food waste." Journal of Cleaner Production 76: 106-115. 
Pinstrup-Andersen, Per. 2002. „Food and agricultural policy for a globalizing world: preparing for the future." The American Journal of Agricultural Economics 84 (5): 1201-1214.

Prakash Shetty. 2006. „Malnutrition and Undernutrition.” Medicine 34 (12): 524 529.

Swinburn, Boyd, and Garry Egger. 1999. „Dissecting obesogenic environments: the development and application of a framework for identifying and prioritizing environmental interventions for obesity.” Preventive Medicine 29 (6): 563-570.

Swinburn, Boyd A, Gary Sacks, Kevin D Hall. 2011. "The global obesity pandemic: shaped by global drivers and local environments." The Lancet 378 (9793): 804814.

Tillotson, James E. 2004. „America's obesity: conflicting public policies, industrial economic development, and unintended human consequences." Annual Review of Nutrition 24: 617-643.

United Nations Children's Fund (UNICEF). 2009. „Tracking progress on child and maternal nutrition: a survival and development priority.” New York.

Retrieved July 27, 2017

(https://www.unicef.org/publications/files/Tracking_Progress_on_Child_and_M aternal_Nutrition_EN_110309.pdf).

United Nations System Standing Committee on Nutrition (UNSCN). 2010. „6th report on the World nutrition situation.” Retrieved July27,2017(https://www.unscn.org/files/Publications/RWNS6/html/).

Waterlander, Wilma E., ClionaNi Mhurchu and Helen Eyles. 2017. „Food Futures: Developing effective food systems interventions to improve public health nutrition.” Agricultural Systems. Retrieved July 27, 2017 (https://doi.org/10.1016/j.agsy.2017.01.006)

World Health Organization (WHO). 2004. „Iodine status worldwide: WHO global database on iodine deficiency." Geneva, World Health Organization. Retrieved July 27 (http://apps.who.int/iris/bitstream/10665/43010/1/9241592001.pdf).

World Health Organization (WHO). 2009. „Global prevalence of vitamin A deficiency in populations at risk 1995-2005”. Retrieved July27,2017. (http://apps.who.int/iris/bitstream/10665/44110/1/9789241598019_eng.pdf).

World Health Organization (WHO). 2014a. „Global report 2012. Mortality attributable to tobacco." Geneva. Retrieved July27, 2017 (http:// www.who.int/tobacco/publications/surveillance/rep_mortality_attributable/en/)

World Health Organization (WHO). 2014. „Global Health Estimates: Deaths by Cause, Age, Sex and Country, 2000-2012.” Geneva, Retrieved July 27, 2017 (http://www.who.int/healthinfo/global_burden_disease/en/).

World Health Organization (WHO). 2016. „Obesity and Overweight”. Fact Sheet. Retrieved July 27, 2017 (http://www.who.int/mediacentre/factsheets/fs311/en/). 